\title{
Gene expression profiling of the human carcinoma cell line A-431 after 5-aminolevulinic acid-based photodynamic treatment
}

\author{
SANDRA RUHDORFER*, RENATA SANOVIC*, VERONIKA SANDER, \\ BARBARA KRAMMER and THOMAS VERWANGER \\ Department of Molecular Biology, University of Salzburg, Hellbrunnerstr. 34, 5020 Salzburg, Austria
}

Received December 21, 2006; Accepted February 9, 2007

\begin{abstract}
The photosensitizer protoporphyrin IX, endogenously accumulated from the precursor aminolevulinic acid (ALA) as well as other less photodynamically effective intermediates, is a successful agent in photodynamic therapy. Despite encouraging clinical results, the basic mechanisms leading to cell death are not fully understood. To elucidate these fundamentals, the alteration of the gene expression pattern in the squamous cell carcinoma cell line A-431 was studied at different time-points after photodynamic treatment with ALA by cDNA-array technique. Cells were incubated for $16 \mathrm{~h}$ with $100 \mu \mathrm{g} / \mathrm{ml}$ ALA and irradiated with a fluence of $3.5 \mathrm{~J} / \mathrm{cm}^{2}$ resulting in $50 \%$ survival until $8 \mathrm{~h}$ post treatment. RNA was isolated at 1.5, 3, 5 and $8 \mathrm{~h}$ post treatment and from 3 controls (untreated, light only and dark), radioactively labeled by reverse transcription with ${ }^{33} \mathrm{P}$-dCTP and hybridized onto macroarray PCR filters containing PCR products of 2135 genes, which were selected for relevance in carcinogenesis, stress response and signal transduction. Verification of observed expression changes was carried out by real-time RT-PCR. We found a strong induction of expression of the immediate early genes $c$-jun and $c$-fos as well as decreased expression of genes involved in proliferation such as $m y c$, genes involved in apoptosis such as Fas associated via death domain (FADD) and the fibronectin gene for cell adhesion. An apoptosis induction rate of not more than $30 \%$ as proved by apoptosis detection assays and caused by PpIX localization in the membrane was reflected by the expression profile.
\end{abstract}

\section{Introduction}

Photodynamic therapy (PDT) is a most promising novel approach in treatment of tumors and non-malignant diseases.

Correspondence to: Dr Barbara Krammer, Department of Molecular Biology, University of Salzburg, Hellbrunnerstr. 34, 5020 Salzburg, Austria

E-mail: barbara.krammer@sbg.ac.at

${ }^{*}$ Contributed equally

Key words: protoporphyrin IX, ALA, photodynamic, apoptosis, cDNA array, gene expression, real-time PCR
It makes use of a photosensitizer which, by activation with visible light, generates reactive oxygen species (ROS) as well as free radicals and induces destruction of target tissue. Many photosensitizers accumulate selectively in certain target tissues and cells, such as tumors.

The photosensitizer protoporphyrin IX (PpIX), an intermediate in the heme biosynthetic pathway, is endogenously produced by the precursor 5-aminolevulinic acid (ALA) (1). External administration of ALA in excess leads to the accumulation of mainly PpIX in the mitochondria which is relocalized preferably to cellular membranes (2).

ALA-PDT offers several advantages over conventional treatments or even over PDT with external sensitizers: due to the lack of serious side effects, ALA-PDT is well tolerated by patients and can be applied repeatedly without cumulative toxicity (3). PpIX is accumulated selectively in tumor cells and increasing with ALA concentration up to a saturation level. Both properties reduce the risk of overdosage by ALA on normal cells, and overdosage by irradiation is minimized by rapid photobleaching. ALA-PDT is therefore safe for the patients. In general ALA is applied topically, orally or via instillation to inner and outer surfaces of the body. Irradiation with 635-nm light is therefore a non-invasive procedure, which produces excellent cosmetic results (red light effect - low power laser stimulation).

At present, the main clinical ALA-PDT applications using topical administration are to the skin diseases: superficial basal cell carcinoma and actinic keratoses. Squamous cell carcinoma, cutaneous T-cell lymphoma and Bowen's disease have also been treated successfully. Clinical trials are also performed for non-malignant skin pathologies such as inflammatory dermatoses, infectious cutaneous diseases caused by microorganisms (viral, mycotic and protozoic infections), psoriasis, acne and warts (4).

For diagnostic purposes, PpIX fluorescence is a marker for early-stage superficial cancers as well as dysplasias and helps in identifying tumor margins during surgery as in fluorescence guided resection (5). Diagnosis is more widely employed in the above listed fields and for much more indications than therapy.

The mechanisms behind this clinically successful therapy and diagnosis are not yet fully clarified. Exploring the basic processes of ALA uptake in the cell, mitochondrial PpIX formation as well as redistribution, and of photodynamic effects, could significantly contribute to a better understanding, a broader applicability and enhanced efficiency of ALA-PDT. 
Only a few studies tried to explore basic mechanisms and processes of ALA-induced ROS-mediated photodamage in more detail on the gene expression or protein level.

Investigations in our lab by quantitative RT-PCR showed alterations of c-myc and bcl-2 expression kinetics in transformed human fibroblasts up to $24 \mathrm{~h}$ post treatment with ALA-PDT (6). In another study about expression profiling of the carcinoma cell line A-431 at $3 \mathrm{~h}$ following ALA-PDT with a high $\left(15 \mathrm{~J} / \mathrm{cm}^{2}\right)$ irradiation dose $(90 \%$ lethality after $24 \mathrm{~h}$ ), we found upregulation of heat-shock protein 70 , of the immediate early genes p55-c-fos and $c$-jun, and of heme oxygenase-1 also following dark incubation (7).

Protein changes in HL60 leukemia cells after ALA-PDT, investigated by two-dimensional electrophoresis, suggest participation of endoplasmic reticulum $\mathrm{Ca}^{2+}$-binding chaperones and/or $\mathrm{Ca}^{2+}$ signaling in cytotoxicity (8). A further study (9) describes the results of expression profiling, but in a time range of up to only $30 \mathrm{~min}$ after irradiation. The authors found upregulation of dual specificity phosphatase 1 in the validation experiments with RT-PCR. Since the results above contribute only fragments to the understanding of the mechanisms, a more comprehensive study is required.

The aim of the present study was therefore to analyze the modulation of gene expression following photodynamic treatment with ALA/PpIX by the detailed, comprehensive and interlinked approach of time resolved expression profiling, using a human cDNA macroarray with 2135 different genes. This approach should be different from the mentioned studies by choosing different treatment conditions (light dose, posttreatment time-points for analysis, damage processes).

In order to comprise the main time period of gene expression responses following lethal treatment for $>50 \%$ of the cells, temporal changes of all genes were measured between 1.5 and $8 \mathrm{~h}$ after ALA-PDT. The squamous cell carcinoma cell line A-431 was used as a human tumor cell model. Verification of the results was carried out by real-time RT-PCR.

\section{Materials and methods}

Cell culture. A-431 human squamous cell carcinoma cells (ATCC: CRL-1555) were cultivated in DMEM (Dulbecco's modified Eagle's medium) with $4.5 \mathrm{~g} / \mathrm{l}$ glucose supplemented with $4 \mathrm{mM}$ L-glutamine, $100 \mathrm{U} / \mathrm{ml}$ penicillin $+0.1 \mathrm{mg} / \mathrm{ml}$ streptomycin, $1 \mathrm{mM}$ sodium pyruvate, $100 \mathrm{mM}$ HEPES and incubated at $37^{\circ} \mathrm{C}$ in a humid $7.5 \% \mathrm{CO}_{2}$-atmosphere. Since the cell line can be grown without serum, no serum was added to the DMEM in order to avoid rapid release of PpIX into the culture medium (10).

Photodynamic treatment. Cells were incubated for $16 \mathrm{~h}$ with $100 \mu \mathrm{g} / \mathrm{ml} \delta$-aminolevulinic acid [ALA (Sigma, Austria); neutralized with $\mathrm{NaOH}$ ] in DMEM for formation of endogenous protoporphyrin IX (PpIX) according to a previous study (7). As shown in earlier studies with several cell lines [e.g. (10)], the fluorescence of PpIX plotted as a function of increasing ALA concentration showed a plateau due to a saturation effect of the PpIX production after addition of $100 \mu \mathrm{g} / \mathrm{ml}$ ALA.

Therefore a concentration of $100 \mu \mathrm{g} / \mathrm{ml}$ ALA was selected for the following series. Irradiation was carried out with a power density of $25 \mathrm{~mW} / \mathrm{cm}^{2}$ using the dermatological halogen lamp 'Waldmann PDT 1200' with a cut-off filter $<600 \mathrm{~nm}$. This protocol led to the desired cell survival kinetic: at least $50 \%$ of the cells developed (lethal) damage but were still vital until $8 \mathrm{~h}$ post irradiation to ensure isolation of enough intact mRNA for analysis of 4 time-points between 1.5 and $8 \mathrm{~h}$; $24 \mathrm{~h}$ post irradiation cell survival dropped under $50 \%$. For comparison and reference served dark control (ALA-only), light-only control and untreated cells.

Cell viability. In order to establish survival curves, cytotoxicity of the PDT-treatment was tested by propidium iodide uptake of necrotic cells on a flow cytometer (FACS Calibur, BectonDickinson, USA). Cells were detached by Accutase (PAAlaboratories, Austria) and stained with $4 \mu \mathrm{g} / \mathrm{ml}$ propidium iodide (Sigma, Austria).

Localization studies of PpIX were performed with an inverted fluorescence microscope (Olympus IX70) coupled to a sensitive RGB camera (SPOT 2, Visitron Systems, Puchheim, BRD) using an excitation of 480-550 $\mathrm{nm}$ and an emission of $>570 \mathrm{~nm}$. Mitochondria and intracellular membranes were co-stained with $1 \mu \mathrm{M}$ DiOC6 (Molecular Probes, NL) for $30 \mathrm{~min}$. Detection of DiOC6 fluorescence was performed at an excitation of $420-480 \mathrm{~nm}$ and an emission of $>515 \mathrm{~nm}$.

Apoptosis detection. The rate of apoptosis using the selected PDT-protocol was measured by assays for: i) caspase- 3 activity, ii) nuclear condensation/fragmentation by means of sub- $\mathrm{G}_{1}$-peak determination in the cell cycle histogram, and iii) determination of mitochondrial membrane potential with the fluorescence dye JC-1. For each assay cells were detached with Accutase at different time-points post treatment (pt) to detect the maximum apoptosis rate. For caspase-3 activity determination the fluorometric CaspACE ${ }^{\mathrm{TM}}$ Assay System (Promega, USA) was used. Apoptotic cells with sub-diploid DNA content (sub-G $\mathrm{G}_{1}$ ) were detected on a flow cytometer (FACS Calibur) by fixing cells with $70 \%$ ethanol, removal of RNA by RNase treatment $(100 \mu \mathrm{g} / \mathrm{ml})$ and staining of DNA with $40 \mu \mathrm{g} / \mathrm{ml}$ propidium iodide. For verification of results apoptotic as well as vital and necrotic cells were stained with $50 \mu \mathrm{g} / \mathrm{ml} \mathrm{JC}-1$ and analyzed on a flow cytometer (FACS Calibur).

RNA isolation and probe synthesis. RNA isolation and cDNA labeling was performed essentially as described by Aberger et al (11). Briefly, after harvesting, A-431 cells were lysed using TRIzol reagent (Gibco-BRL, USA) and RNA was isolated using the provided protocol. Concentration and purity of each RNA sample were checked by measuring absorbance at $260 \mathrm{~nm}$ and determining the 260/280 nm ratio. Integrity of RNAs was verified by evaluating the rRNA bands in an ethidium bromide-stained $2 \%$ agarose gel electrophoresis.

Labeling of cDNA to high specific activity by reverse transcription was carried out by using $15 \mu \mathrm{g}$ total RNA, $70 \mu \mathrm{Ci}$ $\alpha^{33} \mathrm{P}-\mathrm{dCTP}$ (3000 Ci/mmol, Amersham Biosciences, USA), $10 \mu 1$ 3X labeling buffer (for $200 \mu \mathrm{l}: 120 \mu 1$ 5X RevertAid H Minus $^{\mathrm{TM}}$ reverse transcriptase buffer (MBI Fermentas, LT), $3 \mu 1$ $\mathrm{dATP} / \mathrm{dGTP} / \mathrm{dTTP} 100 \mathrm{mM}$ each, $60 \mu 10.1 \mathrm{M}$ DTT, $0.8 \mu 1$ $1 \mathrm{mM} \mathrm{dCTP}, 10.2 \mu \mathrm{l}$ DEPC treated $\left.\mathrm{ddH}_{2} \mathrm{O}\right)$ and $2 \mu \mathrm{l}$ RevertAid H Minus reverse transcriptase (MBI Fermentas). 
The labeled probes were purified using GFX columns (Amersham Biosciences) according to the manufacturer's protocol. Scintillation-counting was used to measure the incorporation of radioactivity and to verify that samples were labeled equally well.

Array hybridization and data analysis. Macroarray PCR filters consisted of nitrocellulose membranes of 22x22 cm (Hybond $\mathrm{N}^{+}$, Amersham Biosciences) each containing PCR products of 2135 clones in duplicate. These 2135 clones were selected from the human UniGem V2.0 library (Incyte Genomics Inc., USA) for relevance in carcinogenesis, signal transduction, proliferation and apoptosis. After prehybridization for $2 \mathrm{~h}$ at $65^{\circ} \mathrm{C}$, filters were hybridized with labeled and denatured $\left(5 \mathrm{~min}\right.$ at $95^{\circ} \mathrm{C}$ ) cDNAs for 2 days at $65^{\circ} \mathrm{C}$ in pre-warmed hybridization buffer [5X Denhardt's, $5 \mathrm{X}$ SSC, $1 \%$ sodium dodecyl sulfate (SDS)]. Filters were washed for $20 \mathrm{~min}$ at $65^{\circ} \mathrm{C}$ in $2 \mathrm{X} \mathrm{SSC} / 0.1 \% \mathrm{SDS}$, then 2 times in $0.2 \mathrm{X}$ saline-sodium citrate buffer $[(\mathrm{SSC}) / 0.1 \% \mathrm{SDS}]$ and then in $0.1 \mathrm{X} \mathrm{SSC} / 0.1 \%$ SDS, rinsed with $2 \mathrm{X}$ SSC, sealed in Saran-wrap and exposed for 4 days to phosphorimager screens (Fuji, Germany). These screens were then scanned with a BAS READER 1800 II phosphorimager (Fuji). Two arrays were hybridized for each RNA sample yielding 4 hybridization spots per duplicate for statistical analysis.

Image and data analysis. Spot intensities were calculated using the AIDA software (Raytest, Germany) and exported to Microsoft Excel (Microsoft, USA). Data were normalized for total signal intensity and statistically analyzed with the MS Excel add-in 'Significance Analysis of Microarrays (SAM)' (www.stat.stanford.edu/ tibs/SAM) (12). Beside a few exceptions, only genes, where both duplicates were found to be significant by SAM, were considered differentially expressed and subjected to verification of results by real-time RT-PCR.

Real-time RT-PCR. Twenty genes of interest, which were selected according to a minimum expression change of 1.8 and similarity of duplicates, were verified by real-time RT-PCR. Primer design was mainly performed with Vector NTI 6 (InforMax, Inc.) unless using previously published primers (http://www.realtimeprimerdatabase.ht.st). Primers (Table I) were ordered at Biomers (Germany).

Real-time RT-PCRs were carried out with iQ $^{\text {TM }}$ SYBRGreen Supermix (Bio-Rad, Germany) on a Bio-Rad iCycler. Optimal annealing temperatures were determined for each primer pair by checking melting curves and $2 \%$ agarose gel banding of PCR products. For normalization of PCR results of the different samples expression of 4 housekeeping genes was monitored (glyceraldehyde-3-phosphate dehydrogenase, ribosomal protein L13a, $\beta$-actin, cyclophilin E). Relative expression changes were calculated according to the geNorm algorithm (13).

\section{Results}

The study design is described briefly as follows: at first, the optimum PDT-treatment protocol had to be established for expression profiling of the A-431 cells. PpIX formation kinetics were analyzed and PpIX localization recorded. In survival curves, ALA concentration, incubation time and irradiation dose (fluence) were determined, which induce lethal cell damage whilst guaranteeing still intact RNA due to unfinished damage processing for preparation at the time-points of interest post treatment $(\mathrm{pt})$. The final protocol fulfilled the requirements for the pt time-points at $1.5,3,5$ and $8 \mathrm{~h}$. To facilitate the interpretation of the gene expression results, the mode of cell death and the used pathway was determined.

After harvesting for expression profiling, the RNA of treated and control cells was isolated, reversely transcribed and labeled, hybridized to the filters and analyzed under the same conditions for all clones. Confirmation, repeats and modifications of experiments were carried out by real-time RT-PCR with only candidate genes.

PpIX localization, survival and cell death mode. After formation of PpIX in the mitochondria, the sensitizer is relocalized in the cell. Fluorescence microscopy at $16 \mathrm{~h}$ after ALA-application revealed strong PpIX fluorescence in the plasma membrane, but small amounts were found in the cytoplasma in a few distinct accumulations. Co-staining of intracellular membrane systems and mitochondria with DiOC6 did not show a correlation of these organelles with the accumulations, excluding PpIX relocalization to these targets (Fig. 1).

The survival curves are based on the exclusion of propidium iodide by cells with intact membranes and show therefore viable cells as well as the population of apoptotic cells at different times after PpIX formation and irradiation with different fluences (light doses). The data (Fig. 2) reveal an optimum protocol following ALA incubation with $100 \mu \mathrm{g} / \mathrm{ml}$ for $16 \mathrm{~h}$ and irradiation with $3.5 \mathrm{~J} / \mathrm{cm}^{2}$, with respect to the required criteria (see above). Cells were viable to an extent of $50 \%$ at $8 \mathrm{~h}$ after irradiation, but $16 \mathrm{~h}$ later $>60 \%$ of the cells had died.

By analyzing the mode of cell death in particular, 30\% of the cells showed caspase- 3 activity (maximum at $5 \mathrm{~h}$ post irradiation) indicating apoptosis; the other $70 \%$ represented necrotic and living cells. Determination of the sub- $\mathrm{G}_{1}$ area in the cell cycle histogram showed also an apoptotic population of $30 \%$ at $24 \mathrm{~h}$ post irradiation. JC-1 staining of mitochondrial membrane potential confirmed $30 \%$ of apoptosis as early as $2 \mathrm{~h}$ pt with a plateau until $5 \mathrm{~h}$ pt at least. Also light-microscopic inspection of cellular morphology indicated this amount of apoptosis induction (data not shown).

Expression profiling. After hybridization of the samples, spot intensities were calculated using the AIDA software and further evaluated with 'SAM'. The results were normalized using the total signal over all detected spots.

Comparison of ALA-PDT-treated with untreated cells was subjected to the following criteria: $\geq 1.8$-fold change $=$ significant upregulation and $\leq 1 / 1.8$-fold change = significant downregulation. As reference served dark control (ALAonly) and light-only control, which were also compared to untreated cells.

Significant expression changes of a number of genes were found over all time-points after ALA-PDT on the cDNA array (Table II). The number of upregulated genes was approximately constant until $5 \mathrm{~h} \mathrm{pt}$; but at $8 \mathrm{~h}$ pt, no single 
Table I. Primer sequences for real-time RT-PCR.

\begin{tabular}{|c|c|c|}
\hline Gene & GenBank acc. no. & Sequence $\left(5^{\prime}-3^{\prime}\right)$ \\
\hline HMGCR & NM_000859.1 & $\begin{array}{l}\text { fwd CACAACAGGTCGAAGATCAATTTACAAG } \\
\text { rev TTAGTCCTTTAGAACCCAATGCCCA }\end{array}$ \\
\hline C-FOS & NM_005252.2 & $\begin{array}{l}\text { fwd GAGAGCTGGTAGTTAGTAGCATGTTGA } \\
\text { rev AATTCCAATAATGAACCCAATAGATATTAGTTA }\end{array}$ \\
\hline INDO & NM_002164 & $\begin{array}{l}\text { fwd GAGATGTCCGTAAGGTCTTGCCAA } \\
\text { rev CAGTCTCCATCACGAAATGAGAACAA }\end{array}$ \\
\hline JUN & NM_002228 & $\begin{array}{l}\text { fwd CACGGCGGTAAAGACCAGAAGG } \\
\text { rev AACTCACTTCCCAGAGCAGCGG }\end{array}$ \\
\hline $\begin{array}{l}\text { SLC25A3 (mitochondrial carrier; } \\
\text { phosphate carrier), member } 3\end{array}$ & $\mathrm{BC} 051367$ & $\begin{array}{l}\text { fwd GAAGAGTACAGTTGTGAATTTGGCTCCG } \\
\text { rev TTAAGACCCCACCAAAGCCACAC }\end{array}$ \\
\hline ART3 & AI201027 & $\begin{array}{l}\text { fwd AACCCACCCAAATACCTGAAGATAAAA } \\
\text { rev GCATCAAACTACAGAGCAACAAAGAGATTT }\end{array}$ \\
\hline CLK2 & L29218 & $\begin{array}{l}\text { fwd CCTCTTCCAGACCCATGACAACAG } \\
\text { rev TTCTGCTTTCTTGTCTTTCG }\end{array}$ \\
\hline C-MYC & NM_002467 & $\begin{array}{l}\text { fwd AGTGGAAAACCAGCAGCCTCCC } \\
\text { rev GAGGTCATAGTTCCTGTTGGTGAAGC }\end{array}$ \\
\hline FADD & U74301 & $\begin{array}{l}\text { fwd CCTGGGGAAGAAGACCTGTGTG } \\
\text { rev CACTGTTGCGTTCTCCTTCTCTGTG }\end{array}$ \\
\hline $\begin{array}{l}\text { ATP13A3 (Homo sapiens poly A } \\
\text { site DNA) }\end{array}$ & BC106085 & $\begin{array}{l}\text { fwd AGGTGTGGGTTCTACTCAGTGCCATA } \\
\text { rev CCAGACATTTCTGTCCTTTAAGTATGTGC }\end{array}$ \\
\hline IFIT1 (ISG56K) & NM_001001887 & $\begin{array}{l}\text { fwd CCCTGAAAACCCTGAATCCAGC } \\
\text { rev CTTAGGGGAAGCAAAGAAAATGGC }\end{array}$ \\
\hline $\mathrm{CDC} 42$ & AA043554 & $\begin{array}{l}\text { fwd GAAAGAAAAGTGGGTGCCTGAGATAA } \\
\text { rev ACATACTTGACAGCCTTCAGGTACACG }\end{array}$ \\
\hline PGRMC1 & NM_006667 & $\begin{array}{l}\text { fwd GAGTCTCAGTTCACTTTCAA } \\
\text { rev GTGGACTGTTACAAATGATT }\end{array}$ \\
\hline PCNA & AY310163 & $\begin{array}{l}\text { fwd AGGCACTCAAGGACCTCATCA } \\
\text { rev GAGTCCATGCTCTGCAGGTTT }\end{array}$ \\
\hline SEP15 & ВC005294 & $\begin{array}{l}\text { fwd AGCGGTGTCTGCTTTTGGGG } \\
\text { rev } \text { TGAAGCAGGTTGAACTGTCCGAGA }\end{array}$ \\
\hline $\mathrm{CDC} 2$ & ВТ007004 & $\begin{array}{l}\text { fwd TCAGGATTTTCAGAGCTTTGGGCACTC } \\
\text { rev GCCATTTTGCCAGAAATTCGTTTGG }\end{array}$ \\
\hline DEK & ВC035259 & $\begin{array}{l}\text { fwd GAGCCACCAAAAAAGACAGCCAAA } \\
\text { rev GCTTTCTTAACATTGGCACTTTTCACAG }\end{array}$ \\
\hline FN1 & X02761 & $\begin{array}{l}\text { fwd ATGCCGACCAGAAGTTTGGG } \\
\text { rev CCCCACGACCATTCCCAACA }\end{array}$ \\
\hline RB1 & NM_000321 & $\begin{array}{l}\text { fwd AATTTCATCTGTGGATGGAGTATTGGGG } \\
\text { rev GAACGACATCTCATCTAGGTCAACT }\end{array}$ \\
\hline KIAA0720 (TNFRSF 12) & AB018263 & $\begin{array}{l}\text { fwd CTTCCGAGACCAGCAGTACGAGATG } \\
\text { rev GCCCTTGCAGAAGCCCTAAGTACG }\end{array}$ \\
\hline 4 HKGs & & \\
\hline ACTB & ВT019932 & $\begin{array}{l}\text { fwd } \text { TTCCTTCCTGGGCATGGAGTCC } \\
\text { rev } \text { TGGCGTACAGGTCTTTGCGG }\end{array}$ \\
\hline PPIE & BC107736 & $\begin{array}{l}\text { fwd GACTGTGGGGAGTACGTGTG } \\
\text { rev GAAGGGCACATATCCCAAAT }\end{array}$ \\
\hline GAPDH & NM_002046 & $\begin{array}{l}\text { fwd CATGGAGAAGGCTGGGGCTCAT } \\
\text { rev GTGATGGCATGGACTGTGGTCAT }\end{array}$ \\
\hline RPL13A & ВC004900 & $\begin{array}{l}\text { fwd CCTGGAGGAGAAGAGGAAAGAGA } \\
\text { rev TTGAGGACCTCTGTGTATTTGTCAA }\end{array}$ \\
\hline
\end{tabular}



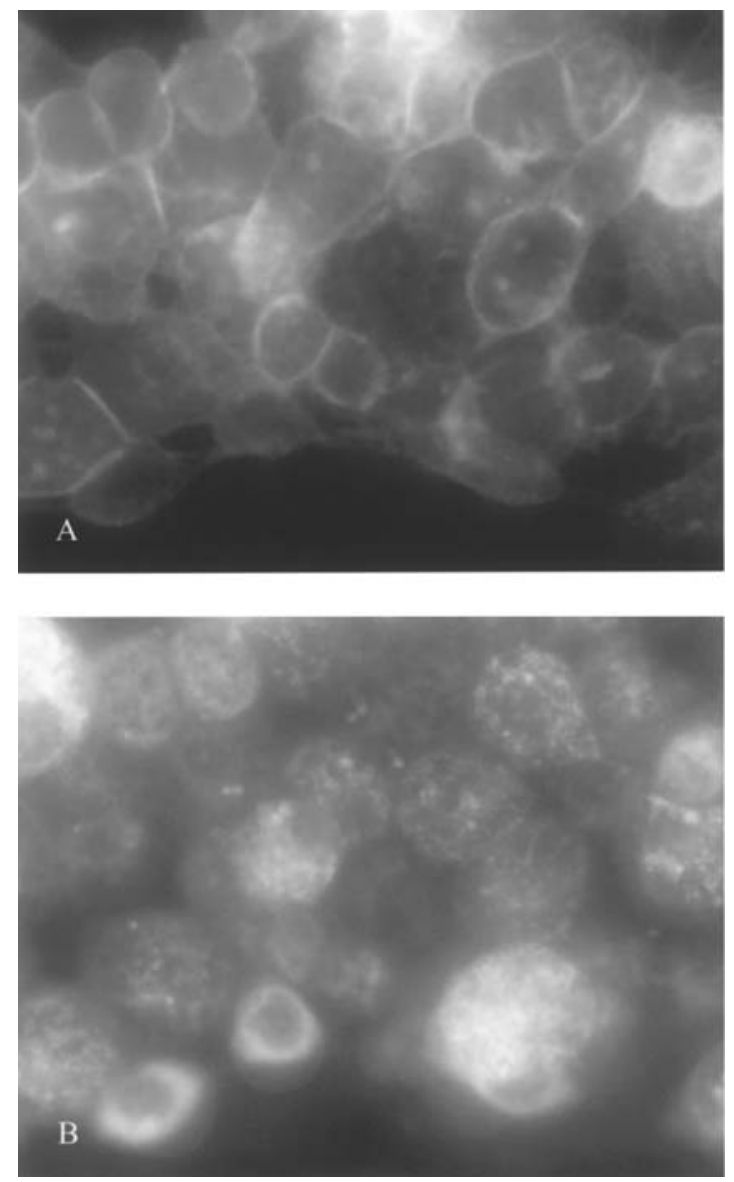

Figure 1. A, intracellular localization of PpIX after 16-h incubation with $100 \mu \mathrm{g} / \mathrm{ml} \mathrm{ALA}$. B, additional staining of mitochondria and intracellular membranes with $1 \mu \mathrm{M}$ DiOC6. Both pictures were taken at a magnification of $\mathrm{x} 1000$ with different filter set-ups.

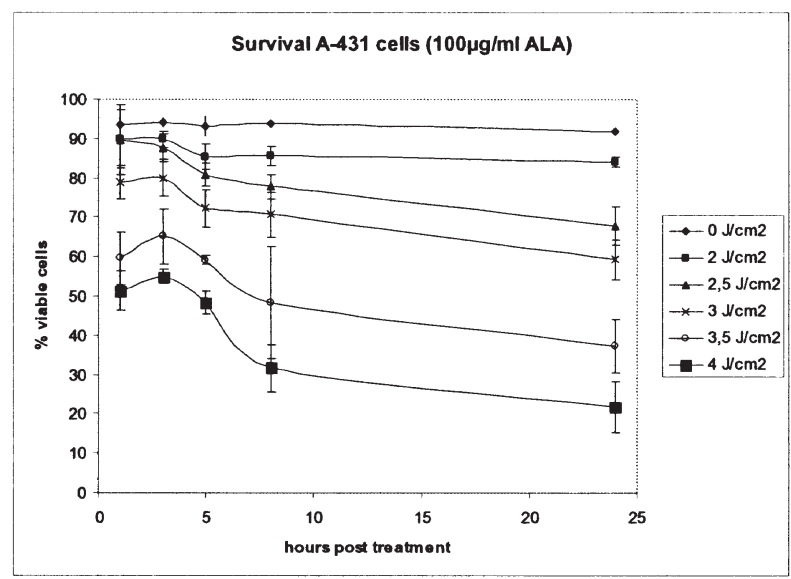

Figure 2. Survival curves of A-431 cells after incubation with $100 \mu \mathrm{g} / \mathrm{ml}$ ALA for $16 \mathrm{~h}$ and irradiation with different fluences.

upregulation could be found. In contrast to this, the number of downregulated genes increased with the time pt.

Since the resulting values of the cDNA arrays can only give a more qualitative than quantitative estimation for changes of the gene expression, the results had to be verified by a truly quantitative technique, for which we chose real-time RT-PCR.
Table II. Quantity of upregulated and downregulated genes on cDNA-arrays.

\begin{tabular}{lcccc}
\hline $\begin{array}{l}\text { Time } \\
\text { pt in h }\end{array}$ & Upregulated & $\begin{array}{c}\text { In } \\
\text { duplicates }\end{array}$ & Downregulated & $\begin{array}{c}\text { In } \\
\text { duplicates }\end{array}$ \\
\hline 1.5 & 4 & 3 & 1 & 1 \\
3 & 3 & 2 & 23 & 11 \\
5 & 3 & 3 & 84 & 61 \\
8 & 0 & 0 & 115 & 105 \\
\hline
\end{tabular}

Number of upregulated and downregulated genes [significantly altered in at least one of the duplicates on the array (columns 2 and 4) and in both duplicates (columns 3 and 5)] after PDT (ALA incubation with $100 \mu \mathrm{g} / \mathrm{ml}$ for $16 \mathrm{~h}$ and irradiation with $3.5 \mathrm{~J} / \mathrm{cm}^{2}$ ).

Consequently, all upregulated genes (5) and 15 of the downregulated genes were chosen for verification: 4 of the 5 upregulated genes (c-fos, c-jun, indoleamine-2,3-dioxygenase, 3-hydroxy-3-methylglutaryl-Coenzyme A reductase) showed the highest expression at $1.5 \mathrm{~h} \mathrm{pt}$. A continuous overexpression between 1.5 and $8 \mathrm{~h}$ was only found with fos and indo. The highest expression of the gene for the mitochondrial phosphate carrier was at $5 \mathrm{~h} \mathrm{pt}$.

Downregulated genes were selected by significant changes in the expression on both duplicates. Also, 3 downregulated genes where only one of the duplicates showed a significant decrease were chosen (PCNA, CDC42 and PGRMC1), since they were of high interest for the current study. Table I presents the genes subjected to verification by real-time RT-PCR. Four housekeeping genes [ $\beta$-actin, glyceraldehyde-3-phosphate dehydrogenase (GAPDH), peptidylprolyl isomerase E (cyclophilin E) and ribosomal protein L13a] were used for normalization of the amount of sample material.

Validation experiments provided methodically sound results for 19 genes. In 10 cases the tendency of the array results was confirmed by the results of real-time RT-PCR (Table III). As threshold for significant expression changes a 2-fold upregulation or downregulation was taken, corresponding to a difference of one cycle between replicates in the real-time $\mathrm{PCR}$, which is seen as a reliable variance.

The upregulated genes c-fos and c-jun showed very high overexpression compared to the untreated cells throughout the whole pt time; the maximum found for c-fos (Fig. 3) was 216 times at $1.5 \mathrm{~h} \mathrm{pt}$ and $45-62$ times at the later 3 time-points; for c-jun it was 50 times at $8 \mathrm{~h} \mathrm{pt}$. The downregulated genes showed their minimum in either one or more data points under the threshold, to a different degree and at different times pt.

The CDC2 gene showed one data point under the threshold, with the factor of 0.46 at $8 \mathrm{~h}$ pt. Three time-points of significant but still moderate downregulation to a factor of 0.45-0.48 were found for the RB1 gene between 3 and $8 \mathrm{~h} \mathrm{pt}$ and to a factor of 0.35-0.45 for the PCNA gene between 3 and $8 \mathrm{~h}$ pt. Light-only treatment caused also suppression under the threshold value, to a factor of 0.49 .

The c-myc gene and the selenoprotein gene were both significantly downregulated to a stronger degree: at $3 \mathrm{~h} \mathrm{pt}$ for 
Table III. Fold change of upregulated and downregulated genes determined by real-time RT-PCR.

\begin{tabular}{|c|c|c|c|c|c|c|c|}
\hline Gene name & Accession no. & Dark & Light & $1.5 \mathrm{~h}$ & $3 \mathrm{~h}$ & $5 \mathrm{~h}$ & $8 \mathrm{~h}$ \\
\hline Proto-oncogene protein c-fos & AI810067 & $0.92 \pm 0.24$ & $0.51 \pm 0.14$ & $216.8 \pm 28.28$ & $45.9 \pm 26.3$ & $62.6 \pm 11.48$ & $45.25 \pm 16.59$ \\
\hline Transcription factor AP-1 (c-jun) & AI598150 & $1.41 \pm 0.41$ & $0.86 \pm 0.33$ & $25.05 \pm 4.36$ & $18.2 \pm 6.6$ & $26.2 \pm 4.9$ & $50.7 \pm 16$ \\
\hline $\begin{array}{l}\text { Cell division cycle } 2, \mathrm{G}_{1} \text { to } \mathrm{S} \text { and } \\
\mathrm{G}_{2} \text { to } \mathrm{M}(\mathrm{CDC} 2)\end{array}$ & Y00272 & $0.66 \pm 0.46$ & $0.65 \pm 0.15$ & $0.82 \pm 0.26$ & $0.63 \pm 0.32$ & $0.85 \pm 0.28$ & $0.46 \pm 0.29$ \\
\hline Retinoblastoma 1 (RB1) & L41870 & $0.82 \pm 0.14$ & $0.79 \pm 0.14$ & $0.83 \pm 0.15$ & $0.45 \pm 0.14$ & $0.47 \pm 0.1$ & $0.43 \pm 0.12$ \\
\hline $\begin{array}{l}\text { Proliferating cell nuclear antigen } \\
(\mathrm{PCNA})^{\mathrm{a}}\end{array}$ & H62620 & $0.54 \pm 0.18$ & $0.49 \pm 0.09$ & $0.62 \pm 0.13$ & $0.35 \pm 0.08$ & $0.45 \pm 0.12$ & $0.45 \pm 0.12$ \\
\hline c-myc & AI093842 & $1.34 \pm 0.23$ & $0.59 \pm 0.18$ & $0.66 \pm 0.18$ & $0.25 \pm 0.11$ & $0.87 \pm 0.28$ & $1.05 \pm 0.22$ \\
\hline $15 \mathrm{kDa}$ selenoprotein & AI377408 & $0.73 \pm 0.35$ & $0.34 \pm 0.11$ & $0.84 \pm 0.43$ & $0.22 \pm 0.06$ & $0.81 \pm 0.31$ & $0.82 \pm 0.28$ \\
\hline $\begin{array}{l}\text { Interferon-induced protein with } \\
\text { tetratricopeptide repeats } 1 \text { (IFIT1) }\end{array}$ & M24594 & $0.6 \pm 0.11$ & $0.76 \pm 0.12$ & $0.62 \pm 0.07$ & $0.27 \pm 0.08$ & $0.19 \pm 0.04$ & $0.29 \pm 0.08$ \\
\hline $\begin{array}{l}\text { Fas (TNFRSF6)-associated via } \\
\text { death domain (FADD) }\end{array}$ & U24231 & $0.45 \pm 0.1$ & $0.64 \pm 0.14$ & $0.47 \pm 0.15$ & $0.15 \pm 0.06$ & $0.35 \pm 0.07$ & $0.38 \pm 0.11$ \\
\hline Fibronectin 1 & X02761 & $0.66 \pm 0.21$ & $0.71 \pm 0.23$ & $0.19 \pm 0.1$ & $0.11 \pm 0.03$ & $0.24 \pm 0.08$ & $0.15 \pm 0.07$ \\
\hline
\end{tabular}

Factors of relative upregulation and downregulation of 10 genes found by real-time RT-PCR, based on mean values out of three independent experiments. Light, light only; and dark, incubation with 5-ALA only. ${ }^{a}$ Downregulation found in only one of the duplicates on the cDNA array.

a factor of 0.25 and 0.22 , respectively. c-myc expression returned to the control level at $8 \mathrm{~h}$ pt. It is remarkable that light alone suppressed the selenoprotein gene to a factor of 0.34 .

Significant and strong downregulations of the ifit1 gene at $3 / 5 / 8 \mathrm{~h}$ pt with $0.27 / 0.19 / 0.29$, and both the FADD adaptor and the fibronectin gene for all time-points, with the lowest value at $3 \mathrm{~h}$ pt, were observed. The strongest suppression to a factor of 0.11 was observed with fibronectin. Also after incubation with ALA only, a moderate downregulation of the FADD gene to 0.45 was observed.

\section{Functions of genes with altered expression}

$c$-fos, $c$-jun. Both are immediate-early, stress response and proto-oncogene genes. The gene product of c-fos is a leucinezipper which can dimerize with proteins of the jun family and, together with ATF (activating transcription factor), form the transcription factor complex AP-1, which binds to a common DNA site, the AP-1-binding site (14). AP-1 has a function in stress response, differentiation, modulation of stress-induced apoptosis, cell proliferation and cell survival by signal transduction of growth factors in the cytoplasm to the nucleus via the MAP-kinases signaling pathway $(14,15)$. Expression increase of both genes is inducible by many stimuli such as growth factors, cytokines, neurotransmitters, polypeptide hormones, stress and cell damage and is very often observed as a rather unspecific cellular response.

Cell division cycle 2 (cdc-2). The cdc-2 gene is coding for a protein belonging to the Ser/Thr protein kinase family. It is essential for the transition $G_{1} / S$ and $G_{2} / M$ in the eukaryotic cell cycle (16).

Retinoblastoma 1 (RB1). The RB1 gene is a tumor suppressor gene due to its function as a 'cell cycle break' in the $G_{1} / S$ transition. Its absence promotes neuroblastic tumors of the retina in childhood but also osteosarcoma and lung tumors.

$\mathrm{RB} 1$ is a repressor of the E2F/DP family of transcription factors, which regulate expression of genes involved in cell proliferation and survival. In its activated form binding to the transcription factor E2F, RB1 is inactivated by phosphorylation and releases the transcription factor, which enables progression in the cell cycle.

Proliferating cell nuclear antigen (PCNA). The product of the PCNA gene is a stable cell cycle regulated (synthesized mainly in S-phase) nuclear protein, whose rate of synthesis correlates directly with the proliferative state of normal cultured cells and tissues. All available information indicates that this ubiquitous and tightly regulated DNA replication protein is a central component of the pathway(s) leading to DNA replication and cell division (17).

$c$-myc. The product of the $c-m y c$ gene is a transcription factor playing an important role in different cellular processes such as cell growth, proliferation, differentiation and apoptosis. Mutations, especially chromosome translocations, transform it to an oncogene. c-Myc is as an immediate early growth response gene rapidly induced upon mitogenic stimulation of quiescent cells. Its task is to induce the transcription of many 


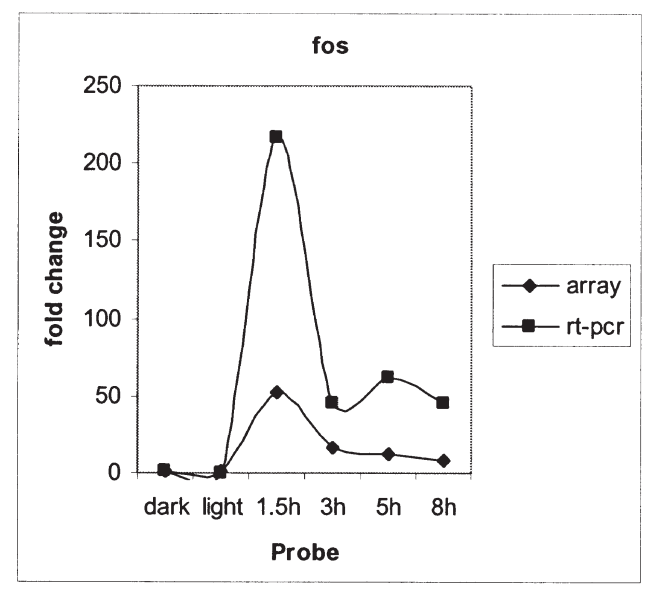

Figure 3. Time course of fos upregulation following ALA-PDT, analyzed by cDNA array and real-time RT-PCR.

cell cycle genes such as cyclins (A, D1, D2, E) and CDKs, which are active in late $\mathrm{G}_{1}$ for transition of $\mathrm{G} 1$ to $\mathrm{S}$ (18). Beside promoting the continuation of the cell cycle, c-Myc can also induce apoptosis in the restriction point of the cell cycle in late $\mathrm{G}_{1}$, if mitogenic stimuli are absent. c-Myc intervenes in the mitochondrial apoptotic pathway via induction of cytochrome c release (19) or via the bcl-2 family (20).

15-kDa selenoprotein. Selenium as an antioxidant trace element (21) has been implicated in cancer prevention, but its possible involvement in this process is not yet understood. Selenoproteins play a role in antioxidant mechanisms, they neutralize ROS, and disturbance of selen biosynthesis leads to accumulation of ROS in the cell (22).

IFIT1 (ISG56K). The ifit1 or isg-56K gene is regulated by interferons, double-stranded RNA and by interferon-inducing viruses (23). The protein has been shown to interact with the eukaryotic translation initiation factor eIF-3 (24).

$F A D D$. The product of the 'Fas-associated via death domain' (FADD) gene as an adaptor molecule is to interact with different cell surface molecules: TNFRSF6/Fas-receptor, TNFRSF10 and 25, and to transmit apoptotic signals to the cell. The receiver is procaspase- 8 , which in the death-inducing signaling complex (DISC) is activated to caspase- 8 . The initiator caspase- 8 again activates a caspase cascade leading to the execution of apoptotic cell death.

Fibronectin. The product of the fibronectin gene is a glycoprotein which in its soluble form can be found in the plasma, and as dimer or multimer on the cell surface or the extracellular matrix, respectively. The protein is involved in cell adhesion, migration processes, wound healing and coagulation, and in metastasis.

The adhesive protein fibronectin and its integrin receptors play an important role in tumor development. Tumor cells are generally less adhesive than normal cells. The loss of matrix adhesion may contribute to tumor cell detachment and metastasis. Normal cells stop growth when adhesion to the neighbour cells or matrix is lost and induce apoptosis (anoikis) (25). Beside soluble plasma fibronectin, a fibrillar extracellular form interacts with intracellular actin filaments on the cellular level. If the fibrils dissociate from the cell surface, the cell rounds up.

\section{Discussion}

Alteration of the gene expression pattern in the squamous cell carcinoma cell line A-431 was studied at the time-points: $1.5,3,5$ and $8 \mathrm{~h}$ after photodynamic treatment with endogenous protoporphyrin IX. Cells were incubated with a protocol resulting in $50 \%$ survival until $8 \mathrm{~h}$ post treatment. After cDNA array analysis and verification with real-time RT-PCR two genes were found to be strongly upregulated and eight downregulated to a different degree.

Genes with altered expression: possible function in ALA-PDT. The immediate-early and stress response genes c-jun and c-fos, forming the AP-1 transcription factor, are generally upregulated by stress and cell damage. The damage set in the cytoplasma by the high amount of ROS and the repair activities following ALA-PDT constitutes cell stress, on which c-jun and c-fos respond by a strongly increased expression over the whole observation period, comparable to the results of our previous study (7).

Due to the photodamage, cell cycle checkpoints prevent cells from progression of $G_{1}$ to $S$ and of $G_{2}$ to $M$ phases in the cell cycle via their downstream targets such as cdc- 2 . This could be the reason for the significant but still moderate downregulation found at $8 \mathrm{~h}$ pt for the cdc-2 gene.

Also significant but still moderate underexpression, but for a longer pt time period of 3-8 $\mathrm{h}$ was detected for RB1. It is unlikely that the tumor suppressor gene and 'cell cycle break' RB1 was downregulated by the cell solely in order to promote proliferation in our study. RB1 seems to play a different role in apoptosis induction: although it is a tumor suppressor gene, its loss induces apoptosis (26). It is likely that RB1 downregulation in the present study supports apoptosis.

Similar to RB1, the PCNA gene was significantly but still moderately underexpressed for all time-points between 3 and $8 \mathrm{~h}$ pt and after irradiation only. Since PCNA correlates directly with the proliferative state of normal cultured cells and tissues, the downregulation of PCNA in the present case could support a proliferation stop after irradiation without much further enhancement by the photodynamic processes. Why irradiation alone has such an effect, cannot be explained without additional experimentation.

The transcription factor $c-m y c$ was significantly downregulated at $3 \mathrm{~h} \mathrm{pt}$ only, demonstrating its rapid reaction to external factors. Such factors could be the loss of mitogenic stimuli, by which $c-m y c$ shuts down cell growth and proliferation and induces apoptosis, or other apoptotic signals.

The selenoprotein gene was significantly downregulated to a major degree but only at $3 \mathrm{~h}$ pt. In addition, light alone suppressed the selenoprotein gene to almost the same level. Could the presence of a rather high concentration of ROS have led to an active downregulation of the selenoprotein in the present study? In this case, ROS would have had to be generated also after irradiation with red light alone. This effect is still to be proved. 
Significant downregulation shows the interferon-induced gene (ifit1 or isg-56K) at the whole time period of 3-8 h. Whether interferons, and which ones, are the inducers needs to be further investigated.

The 'Fas-associated via death domain' (FADD) adaptor gene was significantly downregulated at all time-points, with the lowest value at $3 \mathrm{~h} \mathrm{pt}$. Also after incubation with ALA alone, a significant downregulation was already observed, so photodynamic effects might be partly explained by dark effects of ALA or PpIX.

FADD plays an important role in receptor-mediated apoptosis induced by stimuli such as PDT (27). In spite of this, PDT is found to induce more often the intrinsic apoptotic pathway, as demonstrated by apoptosis induction in the absence of FADD in k/o mice, when Pc 4 was used (28).

Downregulation of FADD could correspond with the rather low amount of apoptosis of only $30 \%$, which seems to be furthermore associated with the mitochondrial pathway.

The strongest suppression compared to the other genes occurred with the fibronectin gene at all time-points. The cell could prepare the rounding-up either for apoptosis or for repair processes. As a consequence, cell detachment and metastasis of surviving cancer cells could result from ALA-PDT.

Expression profile and kinetics. In summary it can be said that ALA-PDT upregulates immediate early/stress genes in response to the damage set by ROS, and downregulates genes with the function of: i) positive (cdc2, PCNA, c-myc) and negative (RB1) control/regulation of proliferation/growth, ii) apoptosis induction (c-myc, FADD, RB1) and iii) cell attachment (fibronectin). A major cell fraction under the surviving cell population of $\sim 60 \%$ between 1.5 and $5 \mathrm{~h}$ or $50 \%$ at $8 \mathrm{~h}$ pt seems to suppress proliferation and apoptosis induction, which points to repair processes, but also, very likely due to lack of intracellular energy caused by leaky membranes, to a tendency of cells to end up in necrotic cell death. The function of the decrease of the antioxidant selenoprotein by irradiation alone and of an interferon-inducible gene in connection with ALA-PDT is not clear and requires further investigation.

The kinetics of downregulation reveals the following: $c$-myc (4-fold) and selenoprotein genes (4.5-fold) show remarkable downregulation only at $3 \mathrm{~h}$, obviously by a rather fast and transient reaction to external stimuli. Other genes are continuously suppressed over a longer pt time, from 3 to $8 \mathrm{~h}$; RB1 and PCNA genes with significant, but still moderate values (not more than 3 -fold) and the ifit-1 gene more strongly, $\sim 5$-fold, possibly due to long-lasting interferon exposure. Suppression over the whole pt time from 1.5 to $8 \mathrm{~h}$ was observed for the FADD gene showing an up to 6.6-fold and for the fibronectin gene showing an up to 9.0-fold downregulation. The cells seem to suppress apoptosis induction and cell adhesion over the whole pt time of analysis. The CDC2 gene displayed significant but no remarkable suppression at only $8 \mathrm{~h} \mathrm{pt}$.

Expression changes of genes with known functions and remarkable alterations: FADD, c-jun, c-fos, c-myc, and fibronectin gene. The entire A-431 population reacts to the ROS stress mainly by strong induction of stress response, by stopping proliferation, suppressing apoptosis, and by supporting detachment of the cells. Subpopulations of still living cells in the apoptotic process, those lethally damaged for necrosis, or sublethally damaged under repair contribute with different, sometimes contradictory signals as shown by the results.

However, the gene expression pattern reflects unrepairable damage, which doesn't allow for apoptosis execution of a population larger than $30 \%$, as found up to $24 \mathrm{~h}$ pt by the different apoptosis detection assays. The suppression of the FADD gene, coding for an adapter in the extrinsic apoptotic pathway, between 1.5 and $8 \mathrm{~h}$ pt demonstrates the low amount of apoptosis and the use of the intrinsic or mitochondrial pathway.

Not only reduction, but total lack of apoptotic processes was one of the main features in the previous study about the gene expression pattern of A-431 cells after ALA-PDT, using a similar incubation protocol, but a 4-fold higher irradiation dose. It was proved by lack of induction or alteration in the expression of genes involved in apoptosis and lack of any other evidence for cell death by apoptosis.

Both studies confirm by intracellular localization recordings that photoactivated PpIX accumulates mainly in the plasma membrane of A-431 cells. Whenever the plasma membrane is the primary target of the photodynamic effect, it is very likely that its destruction prevents apoptotic processes, which depend on intact membranes to assure an unhampered energy balance. In contrast to the former study, where irradiation resulted in necrotic cell death, the lower fluence used in the present study led to minor membrane damage providing a basis for apoptosis induction.

Another study applying macroarrays for determination of changes in the gene expression pattern in ALA-PDT-treated HEL and HL-60 cells (8) found apoptosis induction with ALA-PDT using $1 \mathrm{mM}$ ALA for $4 \mathrm{~h}$ and irradiation with $18 \mathrm{~J} / \mathrm{cm}^{2}$ of 'blue light', leading to $90 \%$ viable cells. This is in contrast to our conditions with only $50 \%$ viable cells applying $100 \mu \mathrm{g} / \mathrm{ml}$ ALA for $16 \mathrm{~h}$ and $3.5 \mathrm{~J} / \mathrm{cm}^{2}$ of 'red light'. Furthermore, the results cannot be compared, since in the above mentioned study quantitative array results as well as a verification is missing. As also non-significant expression changes related to less than 2-fold upregulation or downregulation were listed but not verified, it may be assumed, based on our own experience, that some of the results would be different after verification.

We found that induction of the stress response/immediate early genes by PDT with PpIX was enormously effective with c-fos peaking already at $1.5 \mathrm{~h} \mathrm{pt}$ and c-jun at $8 \mathrm{~h} \mathrm{pt}$. A similar reaction of the cells was observed in our former study, where highly increased expression of the immediate early genes $c$-fos and $c$-jun was found at the analyzed time-point $3 \mathrm{~h}$ after irradiation of PpIX in A-431 cells (7).

In contrast to this, c-fos did not exceed a threshold of two at $30 \mathrm{~min}$ pt in the study of Wild et al (9), which due to the different experimental conditions cannot be compared to our study and will be separately discussed below.

Similar reactions of cells to PDT with external porphyrinbased photosensitizers have been already described: not only a transient upregulation of the early response genes c-fos, c-jun, c-myc, and egr-1 was found in exponentially growing fibrosarcoma cells after PDT, but also an activation in the 
dark (29). Strong and prolonged induction of the c-jun and c-fos proto-oncogenes, both coding for the transcription factor activator protein 1 (AP-1) (30), or AP-1 activation was found in HeLa cells after PDT (31).

Since transcriptional activation of $c$-fos and $c$-jun can be induced by elevated intracellular levels of ROS and calcium (32), conditions which are present after ALA-PDT (33), it is very likely that both factors contribute to the increased expression of $c$-fos and $c$-jun found here. Repair activities could make use of calcium, which was found to be increased after PDT for protection against photodamage (34). Oxidative stress, caused by photoactivation of PpIX, which accumulated in the plasma membrane and cytoplasma in the present study, seems to act through protein kinase-mediated signal transduction pathway(s) over JNK and p38 MAPK to activate the two early response genes $(29,35-37)$.

Rather the proliferation stop than the stress response function is reflected by the rapid and transient downregulation of the early-response gene $c-m y c$ only at $3 \mathrm{~h} \mathrm{pt}$. Similar to the former study of our laboratory on gene expression kinetics after ALA-PDT with a sublethal dose (LD: 5\%), where downregulated and upregulated $c-m y c$ expression had returned to

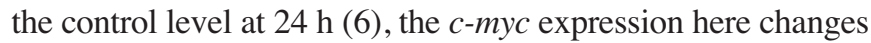
to a high extent only for a limited time period and returns to the control level at $8 \mathrm{~h}$ pt.

The same TGF- $\beta$-receptor, which induces Jun and Fos in the signaling pathway over MKK7 and JNK can also induce $M y c$ over MKK3/6 and p38 in parallel. Therefore a correlation between c-jun and c-fos upregulation and c-myc downregulation is conceivable.

The dramatic downregulation of the fibronectin gene, essential for cell adhesion and migration, may simply characterize the beginning of the rounding up and the detachment process of cells after heavy damage. As a side effect, migration in vitro and metastasis in vivo, respectively, could be facilitated.

After PDT with external porphyrin-based photosensitizers a transient decrease in adhesiveness and in adhesion molecule expression (CD44V6, its lectins and MHC-I) in colon carcinoma cell lines was found, which according to the authors could account for parts of the detected decrease in the metastatic potential of PDT-treated cancer cells (38). Fibronectin downregulation is obviously another factor in the reduction of adhesiveness, but we consider it to be more likely that its downregulation will increase the metastatic potential. Inhibition of cell adhesion by PDT with benzoporphyrin derivative monoacid ring A (verteporfin) was shown in 1997 by Margaron et al (39). Two years later it was demonstrated that downregulation of several adhesion molecules such as fibronectin could be the reason for the transiently decreased adhesion of a human ovarian cancer cell line to collagen IV, fibronectin, laminin and vitronectin after verteporfin photosensitization (40).

Finally, a study of Wild et al about expression profiling of normal and tumor cells following ALA-PDT (9) is not suitable for direct comparison with our results: normal and transformed urothelial cell lines and the HT29 colon carcinoma cell line, treated with ALA-PDT with a dose of LD 50, were harvested 0,10 and $30 \mathrm{~min}$ pt in their study, which cannot be compared with our pt times of 1.5-8 h. The choice of our pt times was based on the fact that immediate-early genes, which represent the first genes expressed after damage setting such as ROS formation, can be found upregulated from $1 \mathrm{~h} \mathrm{pt}$ onwards.

Furthermore, Wild et al selected only three genes for verification with quantitative real-time RT-PCR; the array results of the other genes remain an estimation. Only one of the three genes, the stress-induced DUSP1 gene can be regarded as upregulated by the presented real-time RT-PCR data. Another selected gene for verification by RT-PCR, an apoptosis-relevant gene, showed no expression change. Since also the third chosen gene, c-fos, which is strongly upregulated in our present (216-fold) and also in our former study (7), does not exceed a threshold of two, our opinion that expression profiling before $30 \mathrm{~min}$ is too early seems to be confirmed.

In conclusion it may be stated that ALA-PDT influences significantly the expression of only a few genes and at the same time induces apoptosis in a minor fraction of the whole A-431 cell population. A strong induction of stress response genes, stopping proliferation and apoptosis induction, and a promotion of cell detachment are the main features of the ROS-mediated photodynamic effects of ALA-based PDT.

\section{Acknowledgements}

The authors would like to thank Annemarie Frischauf and Fritz Aberger for their assistance in production of cDNA arrays. The project was supported by the 'Fonds zur Förderung der wissenschaftlichen Forschung', project no. P15143, Austria.

\section{References}

1. Kennedy JC, Pottier RH and Pross DC: Photodynamic therapy with endogenous protoporphyrin IX: basic principles and present clinical experience. J Photochem Photobiol B 6: 143-148, 1990.

2. Krammer B and Uberriegler K: In vitro investigation of ALAinduced protoporphyrin IX. J Photochem Photobiol B 36: 121-126, 1996.

3. Peng Q, Warloe T, Berg K, Moan J, Kongshaug M, Giercksky KE and Nesland JM: 5-Aminolevulinic acid-based photodynamic therapy. Clinical research and future challenges. Cancer 79: 2282-2308, 1997.

4. Szeimies RM, Landthaler M and Karrer S: Non-oncologic indications for ALA-PDT. J Dermatolog Treat 13 (suppl 1): 13-18, 2002.

5. Stummer W, Pichlmeier U, Meinel T, Wiestler OD, Zanella F and Reulen HJ: ALA-Glioma Study Group. Fluorescenceguided surgery with 5-aminolevulinic acid for resection of malignant glioma: a randomised controlled multicentre phase III trial. Lancet Oncol 7: 392-401, 2006.

6. Verwanger T, Schnitzhofer G and Krammer B: Expression kinetics of the (proto)oncogenes $c$-myc and $b c l-2$ following photosensitization of human normal and transformed fibroblasts with 5-aminolevulinic acid-stimulated endogenous protoporphyrin IX. J Photochem Photobiol B Biol 45: 131-135, 1998.

7. Verwanger T, Sanovic R, Aberger F, Frischauf A-M and Krammer B: Gene expression pattern following photodynamic treatment of the carcinoma cell line A-431 analysed by cDNA arrays. Int J Oncol 21: 1353-1360, 2002.

8. Belickova M, Bruchova H, Cajthamlova H, Hrkal Z and Brdicka R: Genes involved in the destruction of leukaemic cells by induced photosensitivity. Folia Biol 46: 131-135, 2000.

9. Wild PJ, Krieg RC, Seidl J, Stoehr R, Reher K, Hofmann C, Louhelainen J, Rosenthal A, Hartmann A, Pilarsky C, Bosserhoff AK and Knuechel R: RNA expression profiling of normal and tumor cells following photodynamic therapy with 5 -aminolevulinic acid-induced protoporphyrin IX in vitro. Mol Cancer Ther 4: 516-528, 2005.

10. Grubinger M, Hammerl P, Banieghbal E and Krammer B: Accumulation of aminolevulinic acid-induced protoporphyrin IX as a photosensitizer in L-929 cells. In: Research Advances in Photochemistry and Photobiology 1, 2000. Mohan RM (ed). Global Research Network, Kerala, pp137-145, 2001. 
11. Aberger F, Costa-Pereira AP, Schlaak JF, Williams TM, O'Shaughnessy RF, Hollaus G, Kerr IM and Frischauf AM: Analysis of gene expression using high-density and IFN-gammaspecific low-density cDNA arrays. Genomics 77: 50-57, 2001.

12. Tusher VG, Tibshirani R and Chu G: Significance analysis of microarrays applied to the ionizing radiation response. Proc Natl Acad Sci USA 98: 5116-5121, 2001.

13. Vandesompele J, De Preter K, Pattyn F, Poppe B, van Roy N, De Paepe A and Speleman F: Accurate normalization of real-time quantitative RT-PCR data by geometric averaging of multiple internal control genes. Genome Biol 3: 0034.1- 0034.11, 2002.

14. Karin M, Liu Z and Zandi E: AP-1 function and regulation. Curr Opin Cell Biol 9: 240-246, 1997.

15. Liebermann DA, Gregory B and Hoffman B: AP-1 (Fos/Jun) transcription factors in hematopoietic differentiation and apoptosis. Int J Oncol 12: 685-700, 1998.

16. Zhao RY and Elder RT: Viral infections and cell cycle G2/M regulation. Cell Res 153: 143-149, 2005.

17. Celis JE, Madsen P, Celis A, Nielsen HV and Gesser B: Cyclin (PCNA, auxiliary protein of DNA polymerase delta) is a central component of the pathway(s) leading to DNA replication and cell division. FEBS Lett 220: 1-7, 1987.

18. Vermeulen K, Berneman ZN and van Bockstaele DR: Cell cycle and apoptosis (Review). Cell Prolif 36: 165-175, 2003.

19. Juin P, Hueber AO, Littlewood T and Evan G: c-Myc-induced sensitization to apoptosis is mediated through cytochrome c release. Genes Dev 13: 1367-1381, 1999.

20. Dang CV, O'Donnell KA and Juopperi T: The great MYC escape in tumorigenesis (Review). Cancer Cell 8: 177-178, 2005.

21. Chen J and Berry MJ: Selenium and selenoproteins in the brain and brain diseases. J Neurochem 86: 1-12, 2003.

22. Morey M, Corominas M and Serras F: DIAP1 suppresses ROSinduced apoptosis caused by impairment of the selD/sps1 homolog in Drosophila. J Cell Sci 116: 4597-4604, 2003.

23. Wathelet MG, Clauss IM, Content J and Huez GA: The IFI-56K and IFI-54K interferon-inducible human genes belong to the same gene family. FEBS Lett 231: 164-171, 1988.

24. Patzwahl R, Meier V, Ramadori G and Mihm S: Enhanced expression of interferon-regulated genes in the liver of patients with chronic hepatitis $C$ virus infection: detection by suppressionsubtractive hybridization. J Virol 75: 1332-1338, 2001.

25. Ruoslahti E: Fibronectin and its integrin receptors in cancer (Review). Adv Cancer Res 76: 1-20, 1999.

26. Macleod K: Tumor suppressor genes. Curr Opin Genet Dev 10: 81-93, 2002.

27. Granville DJ, Jiang H, McManus BM and Hunt DW: Fas ligand and TRAIL augment the effect of photodynamic therapy on the induction of apoptosis in JURKAT cells. Int Immunopharmacol 1: 1831-1840, 2001.
28. Nagy B, Yeh WC, Mak TW, Chiu SM and Separovic D: FADD null mouse embryonic fibroblasts undergo apoptosis after photosensitization with the silicon phthalocyanine Pc 4. Arch Biochem Biophys 385: 194-202, 2001

29. Luna MC, Wong S and Gomer CJ: Photodynamic therapy mediated induction of early response genes. Cancer Res 54: 1374-1380, 1994.

30. Kick G, Messer G, Plewig G, Kind P and Goetz AE: Strong and prolonged induction of c-jun and c-fos proto-oncogenes by photodynamic therapy. Br J Cancer 74: 30-36, 1996.

31. Kick G, Messer G, Goetz A, Plewig G and Kind P: Photodynamic therapy induces expression of interleukin 6 by activation of AP-1 but not NF-kappa B DNA binding. Cancer Res 55: 2373-2379, 1995.

32. Joseph P, Muchnok TK, Klishis ML, Roberts JR, Antonini JM, Whong WZ and Ong T: Cadmium-induced cell transformation and tumorigenesis are associated with transcriptional activation of c-fos, c-jun, and c-myc proto-oncogenes: role of cellular calcium and reactive oxygen species. Toxicol Sci 61: 295-303, 2001.

33. Gederaas OA, Thorstensen K and Romslo I: The effect of brief illumination on intracellular free calcium concentration in cells with 5-aminolevulinic acid-induced protoporphyrin IX synthesis. Scand J Clin Lab Invest 56: 583-589, 1996.

34. Hubmer A, Hermann A, Überriegler K and Krammer B: Role of calcium in photodynamically induced cell damage of human fibroblasts. Photochem Photobiol 64: 211-215, 1996.

35. Gomer CJ, Luna M, Ferrario A, Wong S, Fisher AM and Rucker N: Cellular targets and molecular responses associated with photodynamic therapy. J Clin Laser Med Surg 14: 315-321, 1996.

36. Ryter SW and Tyrrell RM: Singlet molecular oxygen $\left((1) \mathrm{O}_{2}\right)$ : a possible effector of eukaryotic gene expression. Free Radic Biol Med 24: 1520-1534, 1998.

37. Klotz LO, Fritsch C, Briviba K, Tsacmacidis N, Schliess F and Sies H: Activation of JNK and p38 but not ERK MAP kinases in human skin cells by 5 -aminolevulinate-photodynamic therapy. Cancer Res 58: 4297-4300, 1998.

38. Rousset N, Vonarx V, Eleouet S, Carre J, Kerninon E, Lajat Y and Patrice T: Effects of photodynamic therapy on adhesion molecules and metastasis. J Photochem Photobiol B 52: 65-73, 1999.

39. Margaron P, Sorrenti R and Levy JG: Photodynamic therapy inhibits cell adhesion without altering integrin expression. Biochim Biophys Acta 1359: 200-210, 1997.

40. Runnels JM, Chen N, Ortel B, Kato D and Hasan T: BPD-MAmediated photosensitization in vitro and in vivo: cellular adhesion and betal integrin expression in ovarian cancer cells. Br J Cancer 80: 946-953, 1999. 